\title{
Acquisition of computer literacy skills through self- organizing systems of learning among children in Bhutan and India
}

\author{
Sugata Mitra $^{1} \cdot$ Ritu Dangwal ${ }^{2}$
}

Published online: 5 October 2017

(C) The Author(s) 2017. This article is an open access publication

\begin{abstract}
This article describes a study under the Reaching the Unreached component of the Chiphen Rigpel project between the governments of Bhutan and India. This initiative is an attempt to provide computer literacy to children of Bhutan through setting up "hole in the wall" (HiWEL) Playground Learning Station(s) (PLSs). The study described here involves 14 sites (the experimental group), where PLSs are installed, and another 8 sites (the control group) without PLSs, but having similar demographic and socioeconomic profiling as the experimental group. This article compares the acquisition of computer literacy of school-going children in India with those in Bhutan. Results indicate that Bhutanese children have acquired computer literacy on their own and that their level of computer skills acquisition is similar to that of Indian children when the scores are normalized. This study was done over a one-year period, with results reported for eight months. In addition to verifying the earlier Indian results, this article hints at the fact that, irrespective of ethnicity, culture, and country, an identical—and possibly universal—-selforganized learning mechanism seems to work with children vis-à-vis the Internet.
\end{abstract}

Keywords Literacy · Learning $\cdot$ Hole in the wall · Chiphen Rigpel · Gross National Happiness

We would like to acknowledge Suman Gope, who was actively involved in collecting the research data, and Puneet Dhillon, who helped us proofread the paper at its initial stages.

Sugata Mitra

sugata.mitra@newcastle.ac.uk

Ritu Dangwal

ritud@niit.com

1 School of Education, Communication and Language Sciences, Newcastle University, Newcastle upon Tyne NE1 7RU, UK

2 MindChampion Learning Systems, Ltd., 85, Sector-32, Institutional Area, Gurgaon, Haryana 122 001, India 
Research studies (Mitra 2000, 2003; Mitra and Rana 2001; Mitra et al. 2005) have found that children aged 8-14 years can learn basic computing skills on their own, irrespective of their social, cultural, religious, and intellectual background or their geographical location. These research results indicate a new learning mechanism in connected environments. "Hole in the wall" (HiWEL) studies of children in shared, public spaces provide data that support this theory.

Over the years, based on observations and educational experiments conducted at NIIT (India), educators and others worldwide have come to recognize the HiWEL experiments as a proven model of imparting nonformal education. The pedagogy is based on minimally invasive education (MIE) (Mitra 2003; Mitra and Rana 2001), which uses the learning environment to generate an adequate level of motivation to induce learning in groups of children, without, or with minimal intervention from a teacher (Mitra et al. 2005).

In this article, we report relevant findings from outside India and attempt to demonstrate that "computing skill" is a universal phenomenon, especially in a country like Bhutan, which has its own set of challenges. In the process, we have verified the original HiWEL experiments conducted in India over a decade ago. We divide the article into two sections. The first section evaluates the results of experiments carried out in 22 locations in Bhutan, of which 14 have HiWEL Playground Learning Stations (HiWEL PLSs) and 8 do not. The second provides a comparative analysis of computer-literacy levels of self-taught Bhutanese and Indian children.

\section{Background}

NIIT, Ltd., through its Centre for Research in Cognitive Systems, conducted the original hole-in-the-wall experiments at Kalkaji, New Delhi. Currently, Hole-in-the-Wall Education, Ltd., a subsidiary of NIIT, is continuing this work. The first experiment involved installing computers into openings in brick walls-hence the name "hole in the wall" - in public places. Researchers provided children with computers in their natural environments, such that the children had easy accessibility to the computers in safe and public locations, for their own use, free from adult intervention. The results indicate that children are capable of browsing, playing games, painting pictures, chatting, emailing, constructing documents, and even acquiring formal instruction (Bloomberg BusinessWeek 2000; Cohen 2000; Frontline/World 2002; Inamdar 2004; Mitra 2000, 2003; Wullenweber 2001). Such learning was defined as "minimally invasive", indicating the process: children learnt computing skills with no, or with minimal, intervention from adults.

In the present experiments we repeated the same process in Bhutan, using a more robust engineering design of the original, and which we call Hole-in-the-Wall Education, Ltd., Playground Learning Stations. Each PLS unit consists of a computer mounted into or on a wall or solid structure, using an appropriate frame. In effect, a PLS resembles a bank ATM terminal, but with a larger screen, placed at child height. Each PLS has available a large amount of content, consisting of games, educational programs, videos, etc. Internet access is provided where and when possible. See, for instance, Figures 1 and 2.

According to Mitra and Rana (2001), "acquisition of basic computing skills by any set of learners can be achieved through incidental learning provided the learners are given access to a suitable computing facility, with entertaining and motivating content, and some minimal (human) guidance". They call this "minimally invasive education" (MIE). All the experiments reflected that children learned to use computers and the Internet on their own, irrespective of their intellectual maturity or their social, cultural, or economic backgrounds 
Figure 1 One of the first HiWEL experiments in India

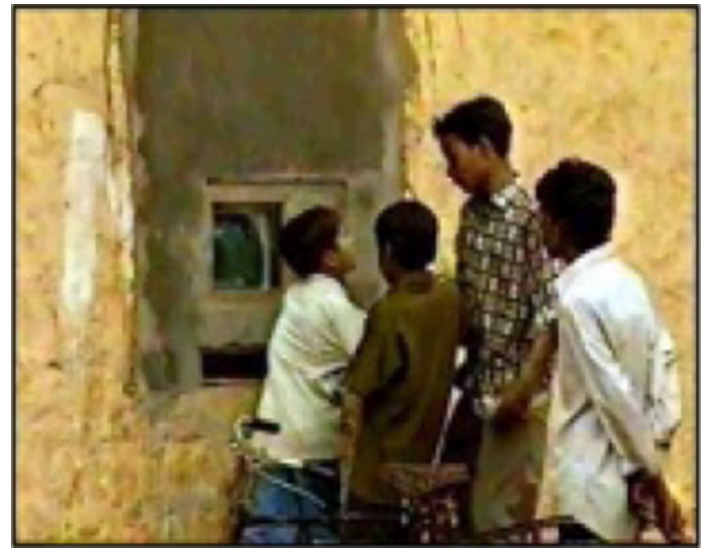

Figure 2 HiWEL PLSs at Madangir, India

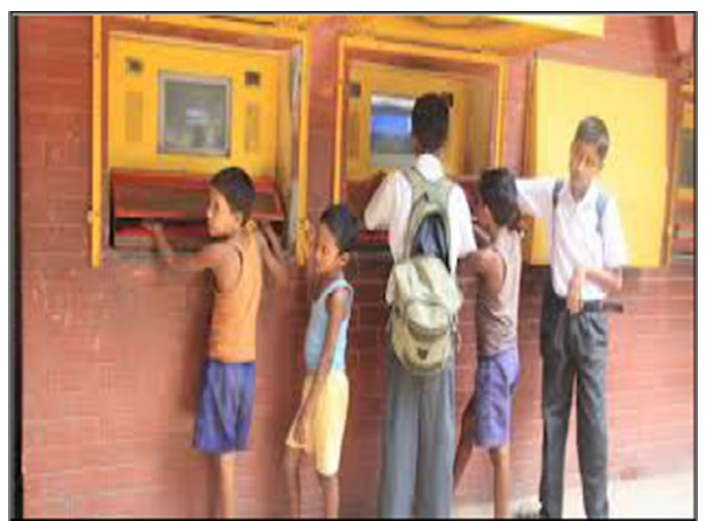

(Mitra and Rana 2001). In an interview with Bloomberg BusinessWeek (2000), Mitra equates computer literacy as the same for children and adults, except the children create their own metaphors to attain computing skills:

The desire of the children to learn and their curiosity drives them to explore the environment in order to satisfy their inquisitiveness. As the children explore the environment they relate their new experience with their previous experience and thereby new learning takes place. The implications of the results of the experiments are not just restricted to computer literacy but education in general.

In subsequent work (Dolan et al. 2013; Mitra and Crawley 2014; Mitra and Dangwal 2010; Mitra and Quiroga 2012), evidence of such learning resulted in the creation of "selforganized learning environments" (SOLEs). SOLEs can reproduce the environment of the hole in the wall inside schools or other enclosed locations and are widely in use by schools around the world. 


\section{Bhutan}

\section{Country profile}

Bhutan, situated in the eastern Himalayas, is a small, landlocked country in southern Asia, between China and India. It has formidable geographical barriers that have made it possible for this country to maintain its unique cultural identity. Bhutan is divided into 4 administrative zones, called Dzongdey, which are further divided into districts, subdistricts, and villages. There are 20 districts, or Dzongkhags, in Bhutan.

Bhutan is not only landlocked but also has one of the most rugged mountainous terrains in the world, with elevations ranging from 100 to 7500 meters. Its population of 716,896 is spread over 38,394 square kilometers $-73 \%$ of which is covered by forests (National Statistics Bureau 2007) - and 90\% of its people live in rural areas. The country's steep, unstable terrains and disseminated population make development policies very fragile and expensive (Tobgay and Wangmo 2008).

\section{The Bhutanese education system}

Since the 1970s, Bhutan has embarked on a very distinctive approach to development: achievement of Gross National Happiness (GNH). According to this concept, development has more dimensions than those associated with GDP or GNP, and it should be understood as a process that seeks to maximize happiness rather than economic growth (Gross National Happiness Commission 2011). The five themes of GNH that serve to direct change in Bhutan are human development, good governance, balanced and equitable development, preservation of culture and heritage, and environmental conservation (Royal Government of Bhutan 2004). Education is considered part of human development; however, the rugged terrain and scattered settlements have made it difficult and expensive for the government to establish formal schools in every community.

\section{Current scenario}

The government of India granted financial assistance to the Royal Government of Bhutan to implement the Chiphen Rigpel (broadly meaning "empowering society, enabling a nation") project. Bhutan initiated this project, initially called "Total Solutions", in 2010 (Ministry of Education 2010) and implemented it over a period of five years in collaboration with the Department of Information Technology and Telecom (DITT), the Ministry of Information and Communications, and NIIT India.

One such program is Reaching the Unreached, which aims to work with the remote population untouched by technology and without access to formal education. NIIT has set up HiWEL PLSs in such locations, installing the computers in a phased manner. In Phase I, NIIT installed 50 PLSs; we selected 14 of these learning sites, primarily in the western and south central region of Bhutan (see Figure 3).

\section{Challenges in Bhutan}

It is important to understand that Bhutan faces certain challenges due to its terrain and other matters, and these impact the usage of HiWEL PLSs. 


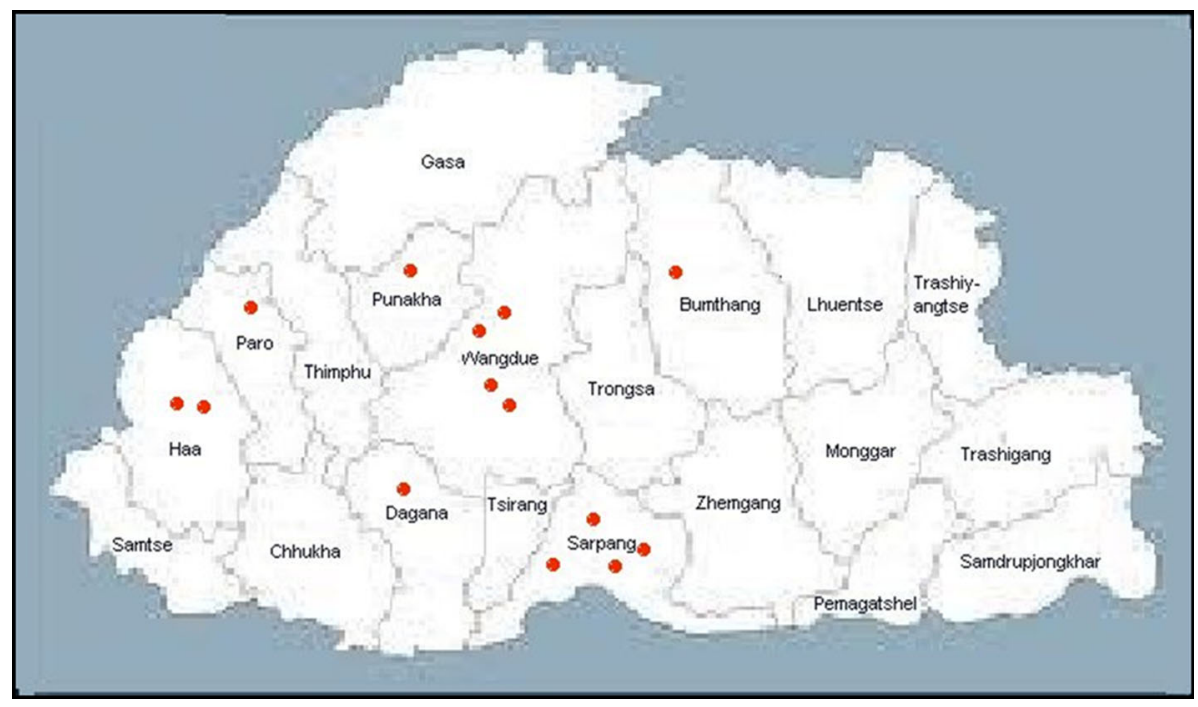

Figure 3 Learning stations installed in Bhutan: Phase 1

Accessibility: The HiWEL PLSs are installed in community centres that are far from schools and children's homes. Hence, children have to walk to these centres to use the HiWEL PLSs, which negatively impact their usage.

Difficult terrain: Schools are fairly remote and children have to walk between 30 minutes to 2 hours to reach school, then again to return to their homes. Thus, they are unable to stay for long at the learning stations.

School hours: In Bhutan, children spend most of their time between $8 \mathrm{am}$ and $4 \mathrm{pm}$ in the schools. Evenings set in early in the mountains, and they have to return before it gets dark. Also, some children need to help their parents in farming or other household activities, a further restriction on time.

Computer access by children: In the schools we studied, the children did not have access to computers. It is possible that, in some rare cases, children may have seen or interacted with a computer at home or on holiday. They may have seen computers on TV.

Operating the PLSs on Saturday and Sundays: Although students would be able to use PLSs on Saturday (half-day school) and Sundays (no school), PLSs are available only on weekdays. As a result, most children visit the PLSs only after school hours, and thus, effectively, have approximately 90-120 minutes to use them.

\section{The study}

\section{Objectives}

The primary objective of our research was to learn whether Bhutanese children aged 8-14 years could acquire computing skills on their own under the circumstances described above.

Our secondary objective was to find out whether it is possible to compare the results obtained under our primary objective with the results of the experiments conducted years 
earlier in India. Such comparison would yield clues to the underlying mechanism for unsupervised learning.

\section{Site location and children's background}

From the 50 sites (near schools) where HiWEL PLSs are operational in Phase 1, we identified 14 sites spread across the western and central areas of Bhutan as our research sites. Children from these sites became the experimental group. We also took 8 sites, in the same regions, where there were no HiWEL PLSs; children from these sites acted as the control group.

The schools are mostly in rural settings; some are in semi-rural settings. The age range of students visiting the PLSs is around 6-14 years, with a mean age of 10-11 years. The majority of the schools offer classes only up through the elementary level (grade 8).

Most of the students come from very poor backgrounds, with parents who are farmers or workers at nearby factories or mining plants. Most parents are illiterate.

\section{Research design}

We based this research on the understanding that computer usage skills are situational (adapted from Gee 2001) and encouraged in collaborative peer situations for autonomy, competence, and relatedness purposes (Deci and Ryan 2012). Thus, it was necessary to adopt a pragmatic philosophy (Onwuegbuzie et al. 2009) that allowed us to intertwine an objective reality (i.e., computer literacy as measured by the Icon Association Inventory Test) and a construed reality (i.e., computer usage is situational, encouraged through social exchanges and therefore observable). We used a standard research design consisting of measuring children's baseline computer literacy and the same at the end of the experiment for the experimental and control groups.

\section{Experimental or focus group}

Twenty-five randomly selected children formed the experimental group at each site. Hence, the total experimental group consisted of a sample of 350 children from the 14 experimental sites (Tables 1 and 2 give the details of the schools and numbers of children).

\section{Control group}

We selected children in the control group from the same districts and having similar socioeconomic features as the experimental group. We chose 25 children from 8 locations, making the total sample size 200. This group did not have access to the HiWEL PLSs (Table 2). However, it is important to mention that while the control group children had no access to the HiWEL PLSs, or to computers in their schools, some of them may have had exposure to computers at home or on holiday. Most would have seen computers at home. Some may have travelled with their parents to areas where the PLSs are present and interacted with the children there. We have assumed that such uncommon and incidental exposure (confounding variables) did not affect the results of our study in any significant way. 
Table 1 Composition of sample experimental group

\begin{tabular}{llll}
\hline Sl. \# & School name & Total sample & Region \\
\hline 1 & Pheunsum Deki Community Primary School & 25 & West \\
2 & Gaselo Lower Secondary school & 25 & West \\
3 & Bjena Community Primary School & 25 & West \\
4 & Tshaphel Lower Secondary School & 25 & West \\
5 & Gyensa Primary School & 25 & West \\
6 & Samtengang Primary School & 25 & West \\
7 & Pelrithang Middle Secondary School & 25 & South Central \\
8 & Lobesa Lower Secondary School & 25 & West \\
9 & Pangna Community Primary School & 25 & South Central \\
10 & Deiking Lower Secondary School & 25 & South Central \\
11 & Sarpang Lower Secondary School & 25 & South Central \\
12 & Jigmechoeling Lower Secondary School & 26 & South Central \\
13 & Tang Lower Secondary School & 25 & South Central \\
14 & Lango Middle Secondary school & 25 & West \\
\hline
\end{tabular}

Table 2 Composition of sample control group

\begin{tabular}{llll}
\hline S1. \# & School name & Total sample & Region \\
\hline 1 & Wangdue Lower Secondary School & 25 & West \\
2 & Chumey Middle Secondary school & 24 & South Central \\
3 & Mendhagang Community Primary School & 25 & West \\
4 & Tencholing Primary School & 25 & West \\
5 & Logodama Primary School & 25 & West \\
6 & Khuruthang Middle Secondary School & 25 & West \\
7 & Jigmeling Lower Secondary School & 24 & South Central \\
8 & Gelephu Lower Secondary School & 26 & South Central \\
\hline
\end{tabular}

\section{Sample size}

The overall sample size is 550 children. Of these, 350 form the experimental group and 200 form the control group.

\section{Tools used}

In order to measure acquisition of computer literacy, we used the Icon Association Inventory Test (Mitra et al. 2005). Researchers developed and reported this test for the original hole-in-the-wall experiments of 2000-2005. The salient points of the test are as follows:

Children's ability to describe the functionality of an icon (in this case, in the Windows Office environment) is directly related to their computing-literacy skills. This is irrespective of whether they use the icon or a drop-down menu. In effect, as they get familiar with an application, such as surfing or word processing, for example, they 
are better able to guess what an icon in the application means, even if they do not use

it. Mitra et al. (2005) demonstrated this with rigorous correlation with other tests.

Test-givers can administer this test with paper and pencil and can administer it outdoors.

A detailed account of the test is available (Mitra et al. 2005), and is not repeated in this article. For the purposes of this study, we took the Icon Association Inventory Test scores as our measure of computer literacy.

Developers devised the Icon Association Inventory Test to measure the ability of children to recognize and associate some of the commonly used computer icons with their functionality. Children form their own vocabulary for naming the icons according to their understanding and use. Keeping this factor in mind, designers made the inventory independent of the name or application associated with the icon. The test asks the children to give a short description in a language that is comfortable for them, stating "what they use the icon for" or "what they associate the icon with". It does not expect or require them to know the names of the icons, but, if they do know, they can write this.

The test contained 77 icons clustered in 5 broad categories based on their functionality: MS Office, generic, Internet, MS Paint, and text format.

\section{Research duration}

The duration of the study was 12 months, but the children had access to the learning stations for a period of 8 months. This was due to school examinations, during which children were not allowed to use the PLSs, which, further, were unavailable during winter due to school vacations. As winters are extreme in Bhutan, most of the families migrate to warmer places.

During this 8-month period, the learning stations were open on weekdays from 9 am to $5 \mathrm{pm}$. And, as explained earlier, the children could use the PLSs for about 90-120 minutes on those days.

\section{Findings}

We report the findings in the following manner: in the first section, we give the overall acquisition of computer literacy, followed by site-wise breakdowns. In the second, we present a comparative analysis of computer literacy between Indian children and Bhutanese children.

Figure 4 (to be read with Tables 3 and 4) indicates that, to begin with, the experimental and control groups were at par (baseline $1 \%$ with standard deviation of $2 \%$ ), indicating that both the groups had little computer literacy. After 8 months, we find a significant difference between the experimental and control groups. The experimental group achieved $15 \%$ computer literacy, while the control group was at $4 \%$. That is, children using the HiWEL PLSs had attained some computer literacy on their own in 8 months.

It is intriguing to note the small increase in computer literacy amongst the control group during the experimental period. Why would children show any increase in computer literacy at all, when they had had no exposure to computers throughout their lives? We do not have an explanation for this small increase in the control group scores, but we speculate that a leakage effect may have caused this increase. It is impossible to find out if the control group children had any interaction at all with the experimental group and/or incidental exposure due to family travel to the experimental sites; and so on. Curiosity 


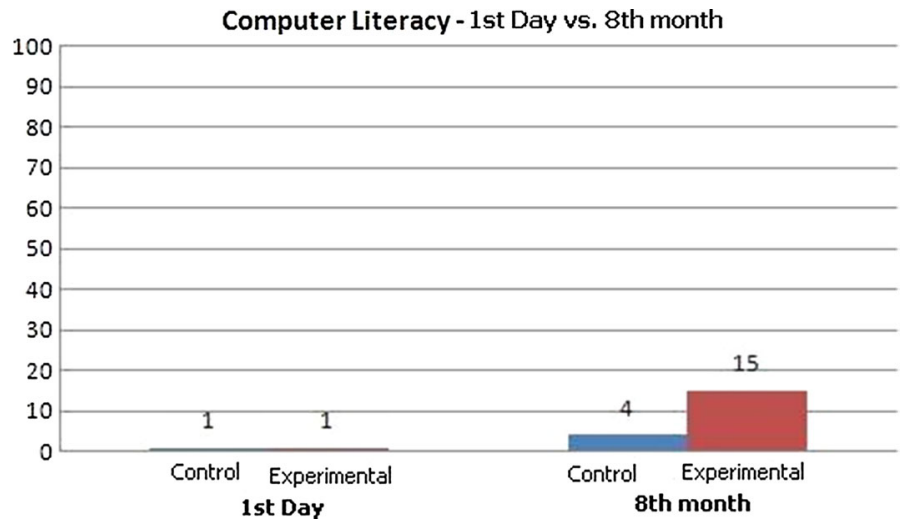

Figure 4 Experimental \& control groups: 1st day vs. 8th month of computer literacy

Table 3 Pre-test: t-test for equality of means (independent sample test)

\begin{tabular}{lllllll}
\hline Pre-test for Computer literacy & $\mathrm{N}$ & $\mathrm{Mean}$ & $\mathrm{Std}$. Deviation & $\mathrm{t}$ & $\mathrm{df}$ & $\mathrm{Sig} .(2-$ tailed $)$ \\
\hline Control Group & 199 & .69 & 1.806 & 1.363 & 549 & .173 \\
Experimental Group & 352 & .51 & 1.300 & & & \\
\hline
\end{tabular}

Table 4 Post-test: t-test for equality of means (independent sample test)

\begin{tabular}{lllllll}
\hline Post-test for Computer literacy & $\mathrm{N}$ & Mean & Std. Deviation & $\mathrm{t}$ & $\mathrm{df}$ & Sig. (2 -tailed) \\
\hline Control Group & 199 & 3.622 & 4.944 & -18.927 & 549 & .000 \\
Experimental Group & 352 & 15.270 & 7.843 & & \\
\hline
\end{tabular}

about the PLSs could have been a major factor as well. If such leakage were indeed the case, we should notice less improvement where travel to a neighbouring PLS site was relatively more difficult and, therefore, less likely. We do, indeed, see a lower (and insignificant) increase in the case of the more rugged terrain of the south-central region, as reported below.

\section{Zone-wise acquisition of computer literacy}

\section{Western region}

Figure 5 (to be read with Tables 5 and 6) indicates the graph for the western region. As one can see from the figure, to begin with the experimental and control groups were at par (baseline), having no knowledge of computers (mean is $1 \%$ and standard deviation is $2 \%$ ). At the end of the experimental period, children having access to HiWEL PLS attained $18 \%$ - an increase of $17 \%$ from the baseline result. In contrast, the control group-i.e., children not exposed to the HiWEL PLS-increased by $4 \%$. 


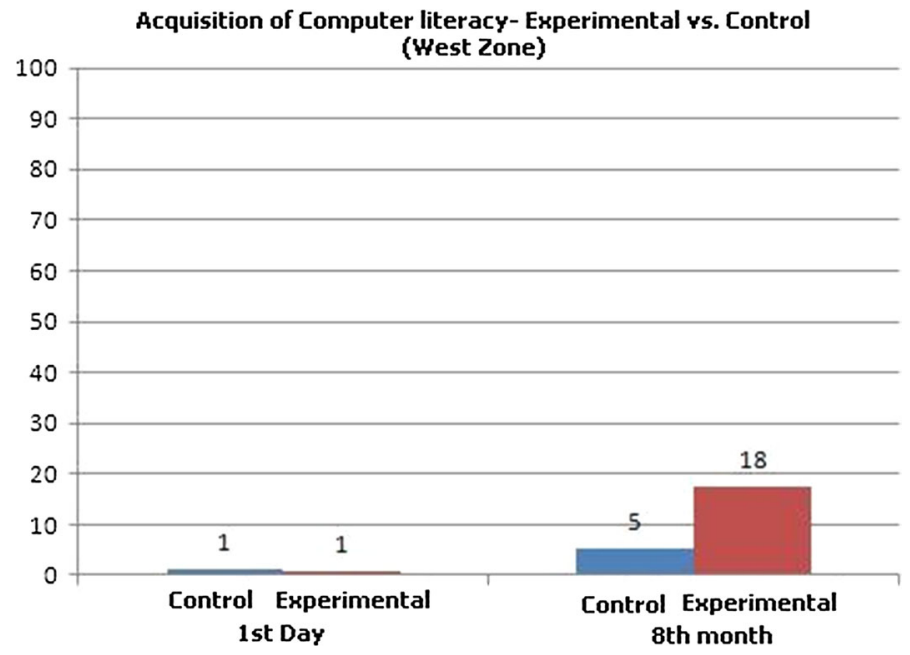

Figure 5 Acquisition of computer literacy, west region: Experimental vs. control

Table 5 Pre-test t-test for equality of means (independent sample test)Pre-test for Computer literacy

\begin{tabular}{lllllll}
\hline & $\mathrm{N}$ & $\mathrm{Mean}$ & Std. Deviation & $\mathrm{t}$ & $\mathrm{df}$ & Sig. (2 -tailed) \\
\hline Control group & 125 & 1.0753 & 2.18361 & 1.668 & 325 & .096 \\
Experimental group & 202 & .7361 & 1.49077 & & & \\
\hline
\end{tabular}

Table 6 Post-test: t-test for equality of means (independent sample test)

\begin{tabular}{lllllll}
\hline Post-test for Computer literacy & $\mathrm{N}$ & Mean & Std. Deviation & $\mathrm{t}$ & $\mathrm{df}$ & Sig. (2 -tailed) \\
\hline Control group & 125 & 5.0649 & 5.64828 & -16.450 & 325 & .000 \\
Experimental group & 202 & 17.4585 & 7.15480 & & \\
\hline
\end{tabular}

\section{South-central region}

Figure 6 (to be read with Tables 7 and 8) indicates the graph for the south-central region. As we see from the figure, to begin with both the experimental and control groups were at par (baseline), having no knowledge of computers. At the end of the experimental period, the experimental group - i.e., children having access to HiWEL PLS-attained 12\%, while the control group-i.e., children not exposed to the HiWEL PLS-increased to $1 \%$. The rugged terrain of the south-central region would have resulted in less, or no, interaction between children at different PLS sites with each other or with control-group children. This may explain the lower improvement in the experimental group as well as the nearly nonexistent improvement in scores amongst the control group. 


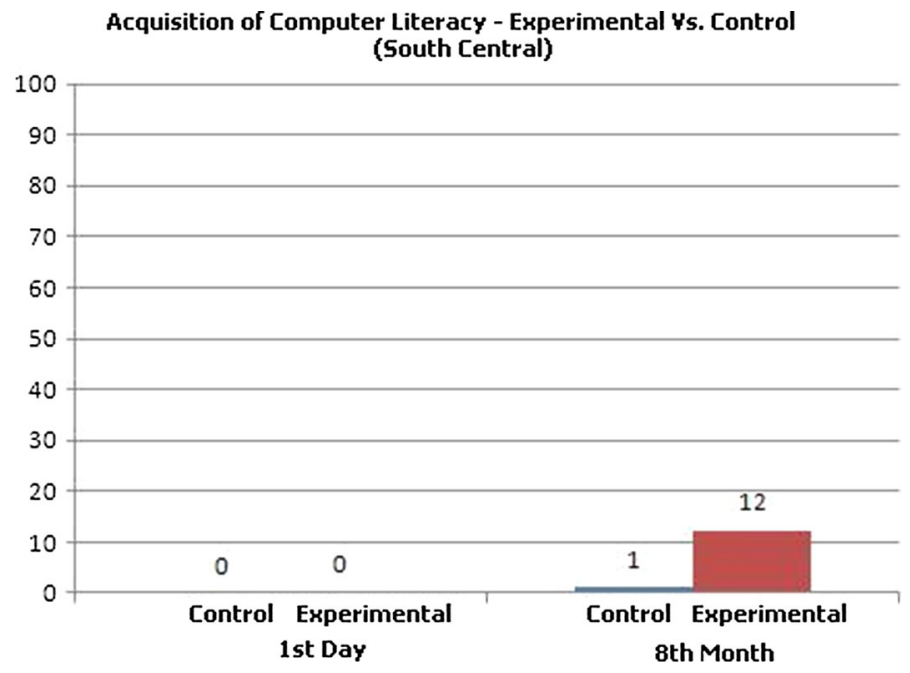

Figure 6 Acquisition of computer literacy, south-central region: Experimental vs. control

Table 7 Pre-test t-test for equality of means (independent sample test)

\begin{tabular}{lrlllll}
\hline Pre-test for Computer literacy & $\mathrm{N}$ & Mean & Std. Deviation & $\mathrm{t}$ & $\mathrm{df}$ & Sig. (2 -tailed) \\
\hline Control group & 74 & .0351 & .23772 & -1.447 & 222 & .149 \\
Experimental group & 150 & .1862 & .88169 & & \\
\hline
\end{tabular}

Table 8 Post-test t-test for equality of means (independent sample test)

\begin{tabular}{lrrrrrr}
\hline Post-test for Computer literacy & $\mathrm{N}$ & Mean & Std. Deviation & $\mathrm{t}$ & $\mathrm{df}$ & Sig. (2 -tailed) \\
\hline Control group & 74 & 1.1846 & 1.58825 & -12.186 & 222 & .000 \\
Experimental group & 150 & 12.3203 & 7.77292 & & \\
\hline
\end{tabular}

\section{Comparative analysis: India and Bhutan}

Using data from the original hole-in-the-wall experiments (Mitra et al. 2005) and the current data from the measurements described in this article, Figure 7 shows that children in India got a starting score of $6.65 \%$; whereas, the children in Bhutan got a score of $0.51 \%$. In other words, the Bhutanese children had almost no prior computer-skills knowledge as compared with the Indian children on the first day of testing.

In the eighth month, Indian children scored $38.18 \%$, while Bhutanese children scored $15.27 \%$. It would appear that Bhutanese children performed poorly compared to Indian children; however, such observation is incorrect. On average, Indian children used the learning stations approximately 4-5 hours per day; while Bhutanese children used them for 1-2 hours per day on average. The reasons for this difference are as follows.

As mentioned earlier, the Bhutanese learning stations are situated in community centers located quite far from the schools and, hence, it is difficult for children to use these 


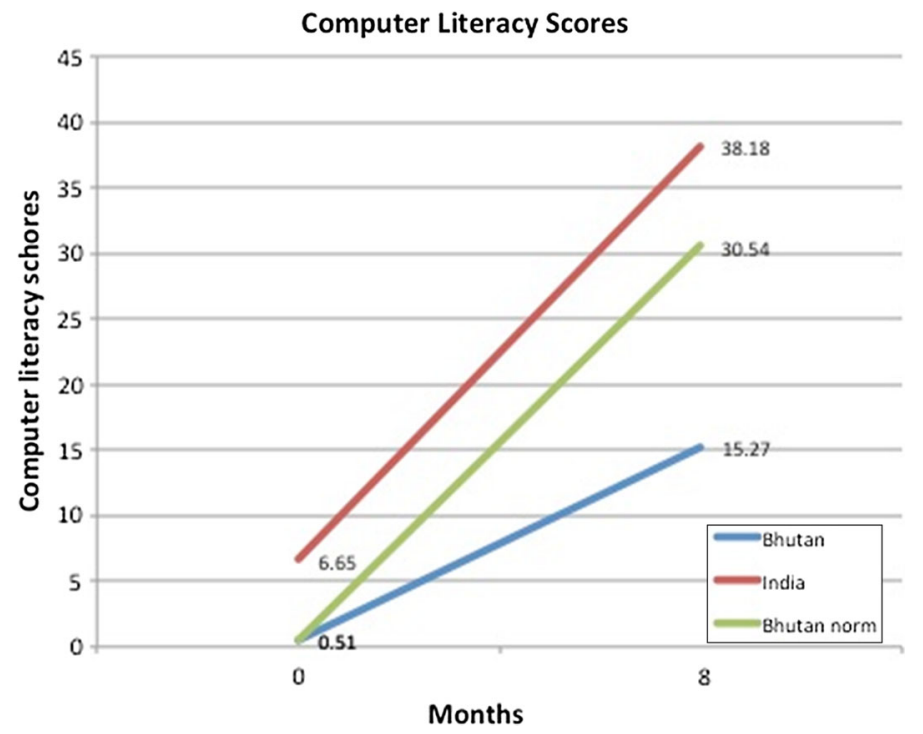

Figure 7 Comparative analysis on acquisition of computer literacy between India and Bhutan, and projected increase for Bhutan

stations. Moreover, these children also walk quite a distance to reach school. Since they are not allowed to miss their classes or go out alone to use these learning stations, this ultimately leaves them with just a few minutes before or after school to use these PLSs. In effect, on average their usage is between 1-2 hours per day. And as noted earlier, Bhutanese students do not have access to these learning stations on the weekends, as schools are closed. Thus, their usage drops when compared with their counterparts in India, who used the learning stations on Saturdays and Sundays, due to the convenience of locations and to the positive attitudes toward learning from a computer within the community. We know from the earlier Indian experiment that children's computer-literacy scores increase with time; i.e, with increase in hours of usage.

Hence, in order to compare the acquisition of computer-literacy skills of Indian and Bhutanese children, we need to normalize the hours of usage figures for Bhutan. We suggest that the achievement of Bhutanese children would double if their usage rate were to double- to 4 hours per day, as was the case for the Indian children.

Figure 7 shows this normalized score, which closely matches the Indian scores. We used straight lines to connect the starting and ending scores. We base such a linear relationship on previous Indian data (Mitra et al. 2005) where monthly observations over several locations for 8 months showed the increase in scores to be linear. Another way to look at the data would be to convert the scores and times into a (linear) "learning rate" (score improvements per unit of usage time).

In the case of India, we estimate the usage over the 8-month period reported at 960 hours ( 8 months $\times 30$ days per month $\times 4$ hours of usage per day). The starting average score was 6.65 while the ending average score was 38.18 , an increase of 31.47 over 960 hours of usage. The learning rate for Indian children is, therefore, a 0.0328 score increase per day of usage.

In the case of Bhutan, we estimate the hours of usage over the 8-month period reported at 480 hours $(8$ months $\times 30$ days per month $\times 2$ hours of usage per day). The starting 
average score was 0.51 while the ending average score was 15.27 , an increase of 14.76 over 480 hours of usage. The learning rate for Bhutanese children is, therefore, a 0.0308 score increase per day of usage.

What is also intriguing in Figure 7 is that the slopes of the Indian and the normalized Bhutanese scores are nearly identical. In fact, if we equalized the starting difference (Bhutan at 0.51, India at 6.65), the two lines would overlap. Could this be an indication that an identical learning process is at work in both experiments? We discuss this briefly in what follows.

In order to get more detailed insight into the working of the learning station, we took anecdotes from the teachers and Principals that helped shape their perceptions about the PLS. These interviews happened in March 2011. We also studied the applications used by the children. A typical classroom environment is shown in Figure 8.

Kailash Subba, ICT-teacher, Samtengang Primary School:

Our students are fortunate enough to experience IT through the "hole in the wall education" initiated by the Ministry. Learning is possible through varied mediums. However, we come across many problems and difficulties in fully utilizing the facilities.

The station is away from the school. This becomes very challenging for them to visit and use those facilities within a period of 40 minutes. It is tiring to walk to the station and come back to their class. In this regard, the school was not in the position to provide a separate class. But students were informed several times about the facilities at the centre and were also instructed to use it during free times.

We would be very grateful if such facilities are provided within the school compound where children will have very easy access and could use it to the fullest.

Sarpang Dzongkhag, vice-principal, Jigmecholing Lower Secondary School:

The establishment of the Gewog Play Ground Learning Station has immensely benefited our children to get attuned and also get firsthand experience with modern technologies. Not only that, it has helped our children spending their leisure time fruitfully. Indirectly it has also help them equipped with the modern world technologies.

Figure 8 Bhutanese children being tested

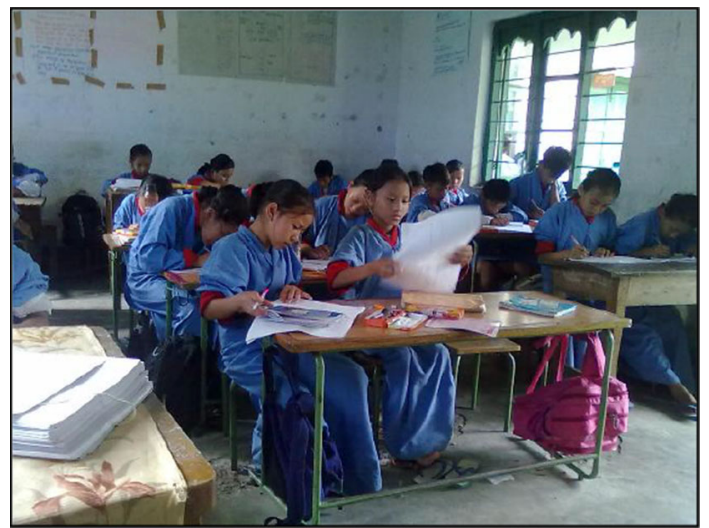


But it would be very useful if the centre is located in our school premises where all the children can avail the facilities and spend ample of time to abreast the facilities.

Chhimi Dorji, Teacher, Phuensum Deki Community Primary School:

The HiWEL PLS under Phangyuel Gewog, Wangduephodrang Dzongkhag, has really benefited the students of Phuensum Deki Community Primary School a lot in terms of computer literacy and other academic related subjects from every aspect. It not only made our children learn the basic computer skills but also help our children guide through their lessons with information from the PLS.

It's really a worth having, it help us reach the unreached, so we are further looking in having such programmes continue in the future for the benefit of our children. We really pay our heartfelt gratitude to Chiphen Rigphel Project (HiWEL) for your kind support in taking our students a step ahead in computer literacy.

Tshering Wangdi, principal, Bjena Community Primary School:

A team member from HiWEL, a subsidiary of NIIT working with MOIC for "Reaching the Unreached" component of Chiphen Rigphel project visited our school and carried out research on children knowledge about the PLS station near school. To my understanding about the nearby station, I should say that this station really benefits our school in many ways as:

Opportunity using ICT knowledge practically.

Guided learning/ independent learning.

Learn through enjoyment.

Teacher shortage problem solved.

Could see vast changes in children before and after the use of this station.

All the staff members of Chiphen Rigpel are supportive to the school at any time we try to get/seek support, the school is very much thankful to the concern office for all the support that we received till now.

Our children will further enhance the knowledge of ICT through the use of facility available.

Therefore, the school would like to thank the concern project director, Chiphen Rigphel Project, project manager, HiWEL, NIIT Thimphu and the concern station supervisor for all support we received as, when asked for. Really took advantage of getting support related to ICT facility available in the school.

Yeshi Seldon, principal, Sarpang Lower Secondary School:

Sarpang Lower Secondary school is highly grateful for installing the HIWEL programme which is about three KM. away from the school. However, the school is not able to benefit much for the reasons that it is bit too far away for the children and teachers reach. There are some children coming from the locality but there too the feedback from them is that it is closed by the time they return home in the evening. Therefore, we would like to suggest the concerned project that HIWEL programme should be nearby the school for the maximum benefit of the students and teachers as well. Further the technology skills of the IT personnel appointed by Chiphen Rigphel at the schools would be utilized to the maximum. 

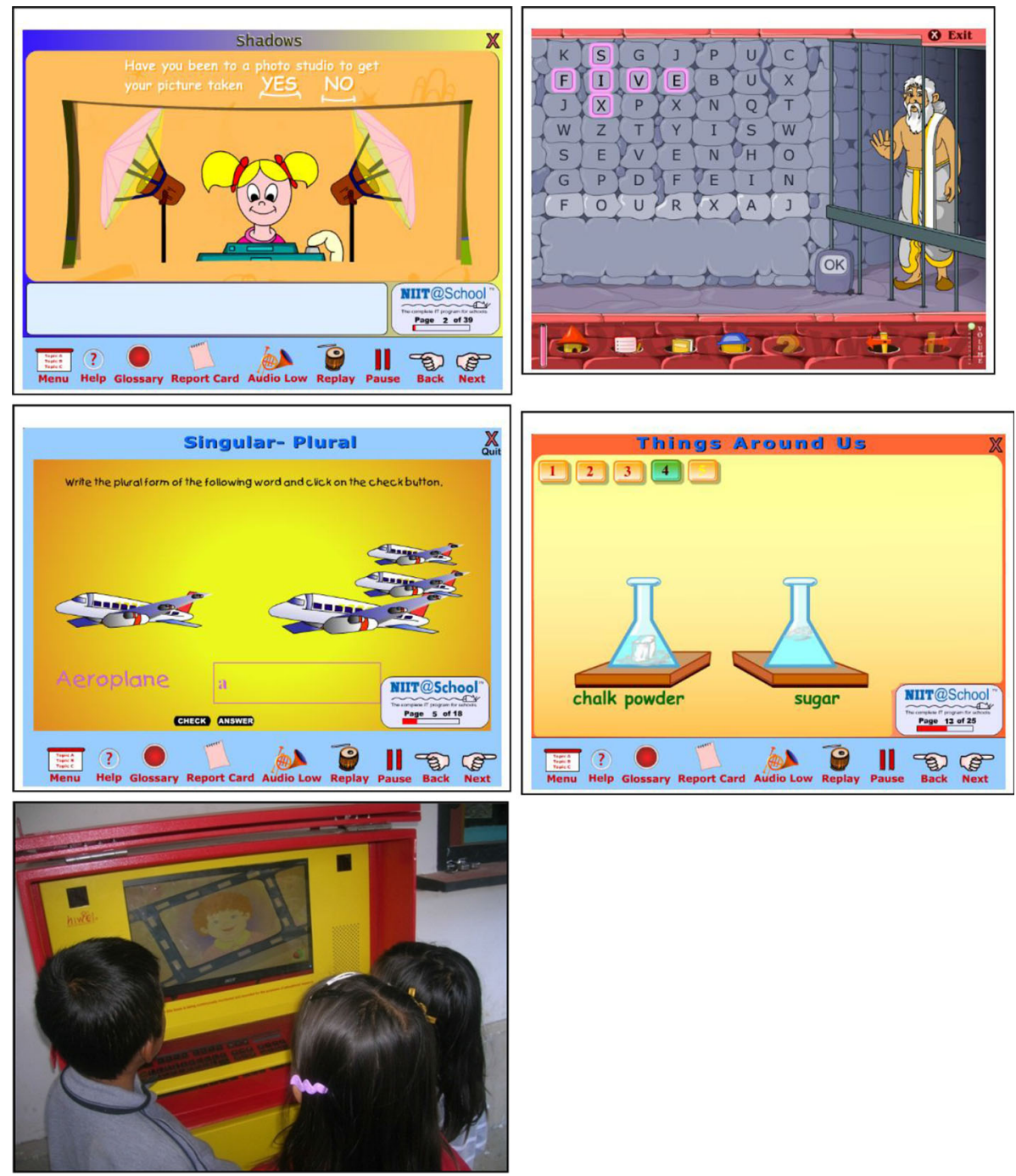

Figure 9 Screen-capture samples from applications used by children

\section{Remote monitoring system}

A remote monitoring system captures the data related to usage of applications and content at the PLS; it indicates that children have been using the PLS (see Figure 9).

\section{Conclusion}

This research started with a primary objective to study whether groups of children aged 8-14 years were able to achieve computer literacy on their own when provided access to PLSs. Our findings indicate that children exposed to the PLSs gained statistically 
significant higher levels on computer literacy when compared with children not exposed to PLSs. In other words, with a confidence level of $95 \%$ one can conclude that computer literacy amongst children in Bhutan has improved through children's use of HiWEL PLSs. The data also suggest that the gain in computer literacy can be increased by enhancing the opportunities for children to use computers.

The PLSs have been placed at community centers, many of which are quite far from the school/s. As a result, children face greater difficulties accessing these facilities after school hours. We have also observed that many schools do not allow the students to visit the PLSs during lunch breaks, for various reasons. If the schools played a more proactive role in allowing children to use the PLSs during school hours, the data suggest that the impact on children would be larger.

It is interesting to discuss why the rates of progress in this Bhutan study and in the older Indian experiments are so nearly identical. One of us (SM) has observed and documented unsupervised learning amongst groups of children using the Internet, in many different contexts and in many countries (Dolan et al. 2013; Mitra 2014; Mitra and Crawley 2014; Mitra and Dangwal 2010; Mitra and Quiroga 2012). Such learning is variously described as "minimally invasive education" and "self-organized learning environments" (SOLEs).

We suggest that the processes we are observing in these diverse unsupervised situations are examples of self-organizing systems (also called "complex, dynamical systems" in the natural sciences and mathematics). "A complex system is any system featuring a large number of interacting components (agents, processes, etc.) whose aggregate activity is nonlinear (not derivable from the summations of the activity of individual components) and typically exhibits hierarchical self-organization under selective pressures" (School of Informatics and Computing 1999).

Complex systems show "emergent properties" or "spontaneous order", and we suggest that this is one of the mechanisms at work in SOLEs. The behavior of the child operating the computer in a PLS is affected by the surrounding children who are observing and advising the operator. Responses from the computer and the Internet, in turn, affect the further actions of the operator and his or her advisors. In other words, the state of each child affects the states of all other surrounding children; what the computer and the Internet display further modify these collective, dynamic states. The collective acts as a complex dynamical system, moving from one equilibrium to another, each time producing spontaneous order in the form of learning.

More research may clarity this fascinating, topical, and alternative form of learning that is so affecting our world of children and the Internet.

Open Access This article is distributed under the terms of the Creative Commons Attribution 4.0 International License (http://creativecommons.org/licenses/by/4.0/), which permits unrestricted use, distribution, and reproduction in any medium, provided you give appropriate credit to the original author(s) and the source, provide a link to the Creative Commons license, and indicate if changes were made.

\section{References}

Bloomberg BusinessWeek (2000). Interview of Sugata Mitra. https://www.bloomberg.com/news/articles/ 2013-11-11/the-false-promise-of-classroom-technology.

Cohen, D. (2000). Slum children get free Internet access. The Guardian (17 October). https://www. theguardian.com/education/2000/oct/17/itforschools.schools5.

Deci, E. L., \& Ryan, R. M. (2012). Overview of self-determination theory. In R. M. Ryan (Ed.), The Oxford handbook of human motivation (pp. 85-107). New York, NY: Oxford University Press. 
Dolan, P., Leat, D., Mazzoli Smith, L., Mitra, S., Todd, L., \& Wall, K. (2013). Self-organised learning environments (SOLEs) in an English school: An example of transformative pedagogy? Online Education Research Journal, 3(11). ISSN 2044-0294.

Frontline/World (2002, October). Kids'-eye view: Looking through the hole in the wall. http://www.pbs.org/ frontlineworld/stories/india/kids.html.

Gee, J. P. (2001). Reading as situated language: A sociocognitive perspective. Journal of Adolescent \& Adult Literacy, 44(8), 714-725.

Gross National Happiness Commission, Royal Government of Bhutan (2011). SAARC development goals mid-term review report. http://www.gnhc.gov.bt/wp-content/uploads/2011/12/SAARCDEVELOPMENT-GOALS-BHUTAN.pdf.

Inamdar, P. (2004). Computer skills development by children using "Hole in the Wall" facilities in rural India. Australasian Journal of Educational Technology, 20(3), 337-350.

Ministry of Education, Royal Government of Bhutan (2010). Annual education statistics. http://www. education.gov.bt/documents/10156/12525/Annual+Education+Statistics.

Mitra, S. (2000). Children and the Internet: New paradigms for development in the 21st century. Talk given at the Doors 6 conference of the Doors of Perception, Amsterdam. https://medium.com/web-design-10/review-of-doors-of-perception-6-conference-lightness-2001-aba252bdb43e. Accessed May 30, 2017.

Mitra, S. (2003). Minimally invasive education: A progress report on the "hole-in-the-wall" experiments. British Journal of Educational Technology, 34(3), 367-371.

Mitra, S. (2014). The future of schooling: Children and learning at the edge of chaos. Prospects, 44(4), 547-558.

Mitra, S., \& Crawley, E. (2014). Effectiveness of self-organised learning by children: Gateshead experiments. Journal of Education and Human Development, 3(3), 79-88.

Mitra, S., Dangwal, R., Chatterjee, S., Jha, S., Bisht, R., \& Kapur, P. (2005). Acquisition of computing literacy on shared public computers: Children and the "Hole in the Wall". Australasian Journal of Educational Technology, 21(3), 407-426.

Mitra, S., \& Quiroga, M. (2012). Children and the internet: A preliminary study in Uruguay. International Journal of Humanities and Social Science, 2(15), 123-129.

Mitra, S., \& Rana, V. (2001). Children and the Internet: Experiments with minimally invasive education in India. The British Journal of Educational Technology, 32(2), 221-232.

Mitra, S., \& Dangwal, R. (2010). Limits to self-organising systems of learning-The Kalikuppam experiment. British Journal of Educational Technology, 41(5), 672-688.

National Statistics Bureau, Royal Government of Bhutan (2007). Statistical yearbook of Bhutan. http:// www.gnhc.gov.bt/absd/?page_id=58.

Onwuegbuzie, A. J., Johnson, R. B., \& Collins, K. M. T. (2009). Call for mixed analysis: A philosophical framework for combining qualitative and quantitative approaches. International Journal of Multiple Research Approaches, 3(2), 114-139.

Royal Government of Bhutan (2004). Bhutan information and communications technology policy and strategies (BIPS). http://unpan1.un.org/intradoc/groups/public/documents/apcity/unpan040891.pdf.

School of Informatics and Computing (1999). Complex systems modelling: Using metaphors from nature in simulation and scientific models. Indiana University website. http://www.informatics.indiana.edu/ rocha/publications/complex/csm.html.

Tobgay, S., \& Wangmo, K. (2008). Can ICT (Internet) overcome the natural geographical barriers of Bhutan in developing the nation? International Journal of Education and Development using Information and Communication Technology (IJEDICT), 4(4), 148-158.

Wullenweber, W. (2001). Das loch in der wand. Stern Magazine, 42, 97-102.

Sugata Mitra (United Kingdom, India) is professor and principal research investigator at Newcastle University in England. He was born in Calcutta, India, in 1952 and is a physicist by training. He has worked on organic semiconductors, energy storage systems, bots, remote presence, complex dynamical systems, and, particularly on the Internet, children, and learning. Since 1999, his experiments on unsupervised learning amongst groups of children, popularly referred to as the "hole-in-the-wall", Self-Organised Learning Environments (SOLEs) and the "School in the Cloud" experiments, have received worldwide attention. He sees the Internet as an enabler for learning to become an emergent phenomenon in the twentyfirst-century-networked environment. He is a recipient of many awards, among them, the million-dollar TED Prize in 2013.

Ritu Dangwal (India) has a PhD in organizational psychology and is a certified counselor. She heads the Design \& Development division of MindChampion Learning Systems, Ltd., a subsidiary of NIIT, Ltd., in 
New Delhi, India. Prior to this, she was project coordinator for the School in the Cloud, TED Prize Project 2013-2016. She has been actively involved in finding innovative, alternative ways of educating children in urban, semi-urban, and remote areas through technology. She was involved in the Hole in the Wall project and has worked and published with Professor Sugata Mitra for over 20 years. 